\title{
Utilization patterns of antihypertensive drugs in the management of hypertension among patients with chronic kidney disease at a tertiary hospital
}

\author{
Abdulrahman Al-Mirza, Hamad R. Al-Subhi, Aly M. Abdelrahman*
}

Department of Pharmacology and Clinical Pharmacy, College of Medicine and Health Sciences, Sultan Qaboos University, Muscat, Oman

Received: 10 March 2021

Revised: 05 April 2021

Accepted: 06 April 2021

\section{*Correspondence:}

Dr. Aly M. Abdelrahman,

Email: abdelrahman@squ.edu.om

Copyright: (c) the author(s), publisher and licensee Medip Academy. This is an open-access article distributed under the terms of the Creative Commons Attribution Non-Commercial License, which permits unrestricted non-commercial use, distribution, and reproduction in any medium, provided the original work is properly cited.

\begin{abstract}
Background: Objective of the current investigation was to identify the utilization patterns of antihypertensive drugs among hypertensive patients with chronic kidney disease at Sultan Qaboos university hospital.

Methods: This is a retrospective study of the utilization patterns of antihypertensive drugs that were prescribed to 181 hypertensive patients with CKD. Patients' data and drugs' data were collected from the hospital track care system and analysed.

Results: The results show that diuretics were prescribed for $63.53 \%$ of the patients followed by $\beta$-blockers $(61.3 \%)$. Drugs were prescribed orally to $90 \%$ of the patients. Furosemide was prescribed to $55.8 \%$ of patients followed by amlodipine $(55.2 \%)$. The majority of the patients were on multiple antihypertensive medications (84\%). There was no significant difference between drug utilization in patients with albuminuria and those without albuminuria. Among patients with CKD stages two and three, $\beta$-blockers were the most common antihypertensive drugs being utilized. Among patients with stage 4 and stage 5, calcium channel blockers and diuretics were the most common antihypertensive drugs being utilized. The prescription of angiotensin II receptor blockers and direct vasodilators showed a significant difference among different stages of CKD.

Conclusions: This study showed that diuretics were the most commonly prescribed antihypertensive drugs among the study cohort. The majority of the patients were on multiple antihypertensive medications.
\end{abstract}

Keywords: Hypertension, Chronic kidney disease, Drug utilization, Antihypertensive drugs

\section{INTRODUCTION}

Hypertension is a global public health problem considered to be one of the major modifiable risk factors in developing renal and cardiovascular adverse events that result in premature disability and death with significantly rising prevalence worldwide. ${ }^{1}$ Hypertension approximately affects one billion people around the world with a prevalence of $33 \%$ in some middle east countries. ${ }^{2}$ The prevalence of hypertension in Oman was estimated to be $41.5 \% .^{3}$ Hypertension is the second leading risk factor of chronic kidney disease (CKD) after diabetes. ${ }^{4}$ The coexistence of hypertension and CKD was found to be a significant contributor to an overall increase in the incidence of cardiovascular disease among patients with both comorbidities. Approximately $80-85 \%$ of CKD patients were found to have hypertension and about 15.8 $\%$ of hypertensive patients were found to have CKD. The coexistence of both comorbidities results in increasing difficulties to control blood pressure. ${ }^{5}$ 
Antihypertensive medications reduce the associated complications with high blood pressure including myocardial infarction, heart failure and stroke. ${ }^{6}$ Antihypertensive drugs are recommended for CKD patients in the presence and absence of hypertension for their renoprotective and cardioprotective effects. It is recommended to keep blood pressure of hypertensive patients with CKD below 130/80 $\mathrm{mmHg}{ }^{7}$

The first-line agents being used in the treatment of hypertension among CKD patients include angiotensin converting enzyme inhibitors (ACEIs), angiotensin II receptor blockers (ARBs), thiazide diuretics and calcium channel blockers (CCBs). ACEIs and ARBs should be the drugs of choice in the treatment of hypertension among CKD patients with albuminuria. ${ }^{7}$

\section{Aim}

Aim of the present study was to examine utilization patterns of antihypertensive drugs among hypertensive patients with chronic kidney disease at a tertiary hospital in Oman.

\section{METHODS}

\section{Study design and data collection}

A retrospective study was conducted concerning the utilization patterns of ACEI, ARBs, $\beta$-blockers, diuretics, $\mathrm{CCBs}$ and direct vasodilators in the management of hypertension among 181 patients with CKD. Collection of data started by choosing the MRN numbers for 181 patients who were treated during the period between 01 January to 01 July of 2019. Data was extracted from the Trakcare system of SQUH.

The collected data included patients' age, gender, blood pressure, serum creatinine levels, eGFR, urinary albumin, stage of CKD, other comorbidities and other medications. Drugs' data was also collected and included the groups of antihypertensive drugs. The usage of drugs whether in single or multiple combination. Additionally, the utilization patterns of antihypertensive drugs were compared according to the presence or absence of albuminuria as well as the different patterns of utilization of those drugs among different CKD stages. CKD stage were identified by eGFR $\left(\mathrm{ml} / \mathrm{min} / 1.73 \mathrm{~m}^{2}\right)$ as stage 1 : $\geq 90$; stage 2: 60-89; stage 3: 30-59; stage 4: 15-29; stage 5: <15. Controlled blood pressure was considered as blood pressure $<130 / 80 \mathrm{mmHg}$.

\section{Data analysis}

All the collected data were recorded and analyzed using statistical package for the social sciences (SPSS) software (version 23). Data was presented as mean $\pm \mathrm{SD}$, range, and percentages. The categorized data were analyzed using the Chi-square test to determine the relationship between different variables being investigated in which a $p<0.05$ was considered to be significant.

\section{RESULTS}

\section{Patients' demographics}

The study cohort included 111 males and 70 females with a mean age of 62.7 years old (Table 1).

Table 1: Patients demographics.

\begin{tabular}{|c|c|}
\hline Parameters $(\mathrm{n}=\mathbf{1 8 1})$ & Value \\
\hline Age (years; mean \pm SD) & $62.7 \pm 14.7$ \\
\hline \multicolumn{2}{|l|}{ Gender $(\%)$} \\
\hline Males & 61 \\
\hline Females & 39 \\
\hline Systolic BP (mmHg; mean \pm SD) & $140.2 \pm 22.4$ \\
\hline Diastolic BP (mmHg; mean \pm SD) & $72.0 \pm 14.6$ \\
\hline \multicolumn{2}{|l|}{ Hypertension status (\%) } \\
\hline Controlled & 33.1 \\
\hline Uncontrolled & 66.9 \\
\hline Creatinine $(\mu \mathrm{mol} / \mathrm{l} ;$ mean $\pm \mathrm{SD})$ & $213.4 \pm 160.8$ \\
\hline eGFR $\left(\mathrm{ml} / \mathrm{min} / 1.73 \mathrm{~m}^{2} ;\right.$ mean \pm SD $)$ & $34.9 \pm 18.6$ \\
\hline \multicolumn{2}{|l|}{ Albuminuria $(\%)(\mathrm{N}=52)$} \\
\hline Present & 58 \\
\hline Absent & 42 \\
\hline \multicolumn{2}{|l|}{ Other comorbidities (\%) } \\
\hline Diabetes & 65.7 \\
\hline Cardiac disorders & 33.7 \\
\hline Dyslipidemia & 25.4 \\
\hline Pulmonary disorders & 24.3 \\
\hline Blood disorders & 22.7 \\
\hline \multicolumn{2}{|l|}{ Other medications (\%) } \\
\hline Statins & 59.7 \\
\hline Antidiabetic medications & 39.2 \\
\hline Antiplatelet drugs & 37.6 \\
\hline Anticoagulants & 18.2 \\
\hline Bronchodilators & 11.0 \\
\hline \multicolumn{2}{|l|}{ CKD stages (\%) } \\
\hline Stage 1 & 1.1 \\
\hline Stage 2 & 8.2 \\
\hline Stage 3 & 49.7 \\
\hline Stage 4 & 26.5 \\
\hline Stage 5 & 14.4 \\
\hline
\end{tabular}

The majority of the patients were having uncontrolled hypertension, (66.9\%). Urine albumin was reported for only fifty-two patients. Out of those fifty-two patients; $58 \%$ were having albuminuria. The most common comorbidity was diabetes mellitus followed by cardiac disorders and dyslipidemia. The most common groups of drugs that were used along with antihypertensive drugs include statins followed by diabetes medications. Almost half of the study group were located in stage 3 of CKD. 
Utilization of antihypertensive groups of drugs among CKD patients

Diuretics were prescribed for $63.5 \%$ of the patients followed by $\beta$-blockers (61.3\%) (Table 2). The most frequent prescribed drug was furosemide (55.8\%) followed by amlodipine (55.2). Most of the patients received the drugs orally $(90 \%)$ (Figure 1$)$. Most of the patients were on multiple antihypertensive medications (84\%) (Figure 2-3). Among those patients; $27.1 \%$ were using 3 drugs followed by $25.4 \%$ who were using 4 drugs together. $16 \%$ of patients were on single therapy.

Table 2: Antihypertensive drugs utilized by hypertensive patients with chronic kidney disease.

\begin{tabular}{|c|c|c|}
\hline Group of drug & Name of drug & $\%$ of patients using the drug \\
\hline \multirow{5}{*}{ Calcium channel blockers } & Total usage & 60.2 \\
\hline & Amlodipine & 55.2 \\
\hline & Verapamil & 2.2 \\
\hline & Nifedipine & 1.7 \\
\hline & Diltiazem & 2.8 \\
\hline \multirow{6}{*}{ B-blockers } & Total usage & 61.3 \\
\hline & Bisoprolol & 38.1 \\
\hline & Carvedilol & 13.3 \\
\hline & Atenolol & 7.2 \\
\hline & Labetalol & 3.9 \\
\hline & Propranolol & 1.1 \\
\hline \multirow{6}{*}{ Diuretics } & Total usage & 63.5 \\
\hline & Hydrochlorothiazide & 4.4 \\
\hline & Indapamide & 3.9 \\
\hline & Spironolactone & 5.0 \\
\hline & Metolazone & 2.2 \\
\hline & Furosemide & 55.8 \\
\hline Direct vasodilators & Hydralazine & 40.9 \\
\hline Angiotensin converting enzyme inhibitors & Lisinopril & 14.9 \\
\hline \multirow{3}{*}{ Angiotensin receptor blockers } & Total usage & 18.8 \\
\hline & Irbesartan & 16.6 \\
\hline & Valsartan & 2.2 \\
\hline Alpha-1 blockers & Prazosin & 3.9 \\
\hline \multirow{3}{*}{ Alpha-2 agonists } & Total usage & 2.8 \\
\hline & Clonidine & 0.6 \\
\hline & Methyldopa & 2.2 \\
\hline
\end{tabular}

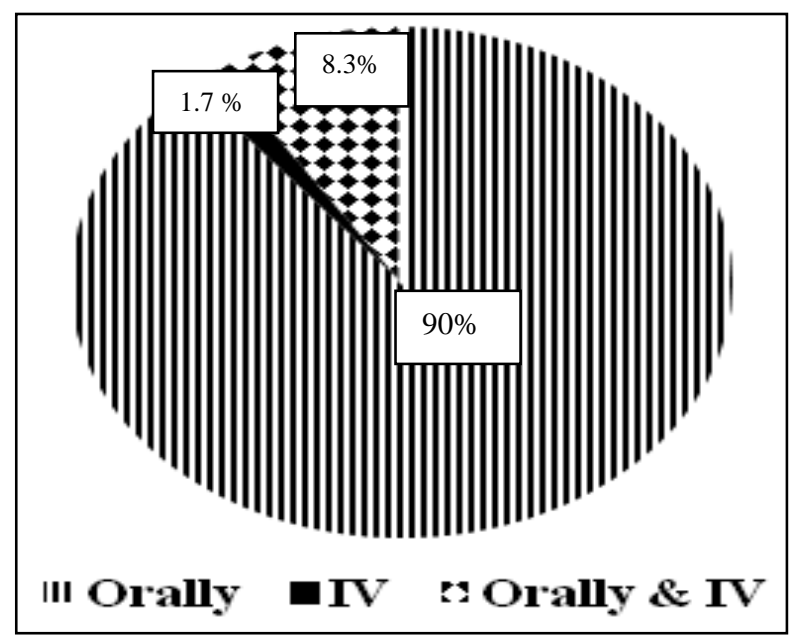

Figure 1: Routes of administration of antihypertensive drugs among chronic kidney disease (CKD) patients, data are shown as percentage of patients.
Utilization of antihypertensive drugs in the presence and absence of albuminuria

Urine albumin was reported for only fifty-two patients out of the total number of patients. There was no significant difference between the prescription of CCBs, diuretics, ACEIs, $\beta$-blockers, ARBs and direct vasodilators among patients with albuminuria compared with patients without albuminuria (Table 3 ).

Utilization of antihypertensive drugs among patients with different stages of $C K D$

Among stage one patients; there were only two patients with equal utilization of ARBs, $\beta$-blockers and direct vasodilators. Table 4 shows there was a significant difference in the prescription of ARBs and direct vasodilators among different stages of CKD. However, there was no significant difference in the prescription of CCBs, diuretics, ACEIs and $\beta$-blockers among the different stages of CKD. 


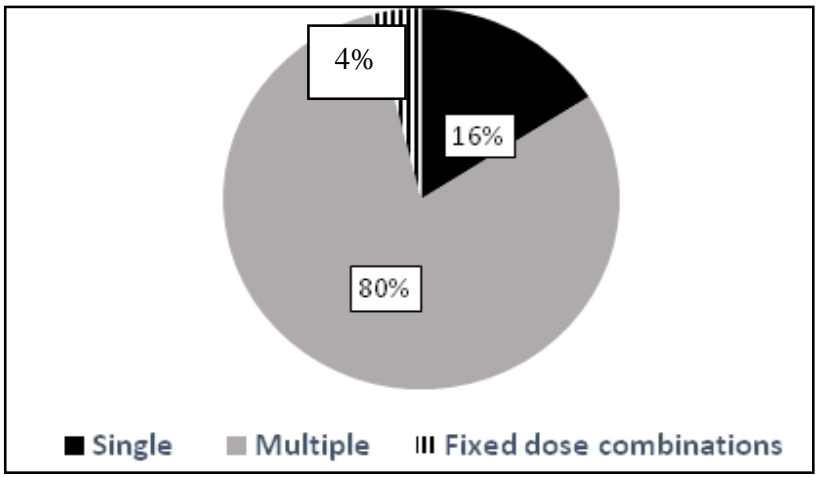

Figure 2: Antihypertensive drugs among hypertensive patients with chronic kidney disease (CKD) patients, data are shown as percentage of patients.

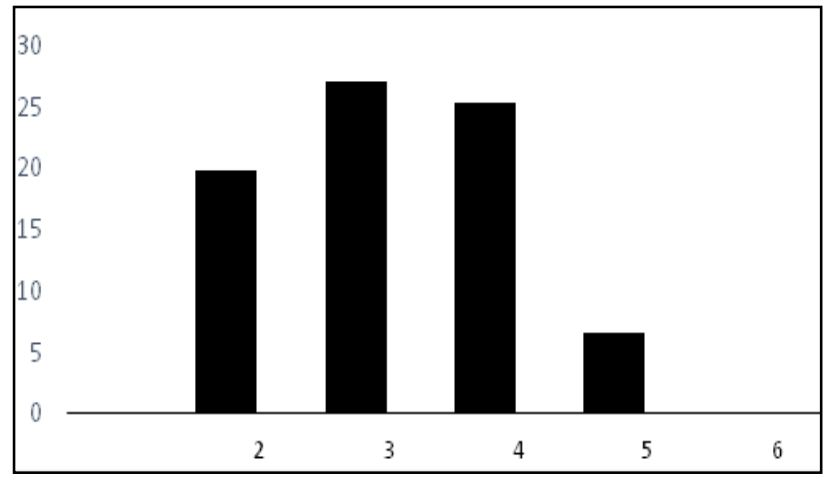

Figure 3: Number of antihypertensive drugs among hypertensive patients with chronic kidney disease (CKD) patients, data are shown as percentage of patients.

Table 3: Utilization patterns of antihypertensive drugs in the presence and absence of albuminuria.

\begin{tabular}{|llll|}
\hline Group of drugs/presence or absence of albuminuria & $\begin{array}{l}\text { With albuminuria } \\
(\%)\end{array}$ & $\begin{array}{l}\text { Without albuminuria } \\
(\%)\end{array}$ & P value \\
\hline Calcium channel blockers & 55.2 & 34.8 & 0.143 \\
\hline Beta-blockers & 63.3 & 63.6 & 0.982 \\
\hline Diuretics & 62.1 & 60.9 & 0.930 \\
\hline Direct vasodilators & 30.0 & 40.9 & 0.414 \\
\hline Angiotensin receptor blockers & 33.3 & 36.6 & 0.820 \\
\hline Angiotensin converting enzyme inhibitors & 6.7 & 18.2 & 0.199 \\
\hline
\end{tabular}

Table 4: Uutilization patterns of antihypertensive drugs in different chronic kidney disease (CKD) changes.

\begin{tabular}{|llllll|}
\hline Group of drugs/CKD stage & $\begin{array}{l}\text { Stage } \\
(\boldsymbol{\%})\end{array}$ & $\begin{array}{l}\text { Stage } \mathbf{3} \\
(\boldsymbol{\%})\end{array}$ & $\begin{array}{l}\text { Stage } \\
(\boldsymbol{4})\end{array}$ & $\begin{array}{l}\text { Stage 5 } \\
(\boldsymbol{\%})\end{array}$ & P value \\
\hline Calcium channel blockers & 50.0 & 52.7 & 68.8 & 76.9 & 0.121 \\
\hline Beta-blockers & 53.3 & 66.7 & 54.2 & 61.5 & 0.621 \\
\hline Diuretics & 42.9 & 61.5 & 68.8 & 73.1 & 0.344 \\
\hline Direct vasodilators & 13.3 & 30.0 & 58.3 & 65.4 & 0.001 \\
\hline Angiotensin receptor blockers & 13.3 & 28.9 & 8.3 & 0.0 & 0.002 \\
\hline Angiotensin converting enzyme inhibitors & 26.7 & 20.0 & 10.4 & 0.0 & 0.058 \\
\hline
\end{tabular}

\section{DISCUSSION}

Current study aimed to identify the utilization patterns of antihypertensive drugs among hypertensive patients with CKD. The results of the present study showed that $66.9 \%$ of the patients were having uncontrolled hypertension. In accordance with our study, a previous study recorded similar results in which $73.5 \%$ of the patients were having uncontrolled hypertension. ${ }^{8}$ This may be explained by the presence of multiple comorbidities that might interact to increase the difficulty of the hypertension treatment approach among those patients.

Diuretics were the most commonly prescribed drugs followed by $\beta$-blockers. However, the recommendations of clinical guidelines include ACEI and ARBs as a firstline therapy for hypertensive patients with CKD particularly for these with albuminuria. ${ }^{7}$ A previous study that showed that $\beta$-blockers were the most commonly used group. ${ }^{9}$ On the contrary, another study showed that ACIs and ARBs were the most commonly used drugs. ${ }^{8}$ This issue may be due to the co-existence of multiple cardiac disorders including heart failure and myocardial infarction. $\beta$-blockers might be required as drugs of choice to treat those cardiac disorders. Diuretics may be needed as the drugs of choice in case of co-existence of heart failure or fluid overload.

In the present study, $84 \%$ of the patients were on multiple antihypertensive medications with a three-drug combination being the most frequent form of combination therapy $(27.1 \%)$ compared to monotherapy $(16 \%)$. Previous studies showed that most hypertensive patients with CKD require multiple combination therapy for their blood pressure control. ${ }^{8}$ In the present study, fixed dose combinations were given to only $4 \%$ of patients. Fixed doses were found to be better than free doses combinations because they enhance and improve 
patient compliance and therefore enhance the outcomes as well as the quality of life. ${ }^{10}$

There was no significant difference between the prescription of CCBs, diuretics, ACEIs, $\beta$-blockers and ARBs among patients with and without albuminuria. In addition, there was no significant difference in prescription of these drugs except ARBs and direct vasodilators between the different stages of CKD. Sonawane et al showed that the use of ACEI and diuretics differed significantly according to the stage of CKD. ${ }^{9}$

\section{Limitations}

Limitations of current study were; there are other comorbidities, which might have affected the utilization of antihypertensive drugs. The entered data were for drugs that were prescribed in the last visit of the patients to the clinic during the time of the study so previous antihypertensive drugs that were discontinued for some patients were not included.

\section{CONCLUSION}

Current study showed that diuretics were the most commonly used group of antihypertensive drugs among hypertensive patients with CKD. Furosemide was the most commonly used drug in this study. Also, there was no significant difference between the prescriptions of all antihypertensive agents being investigated among patients with albuminuria compared with patients without albuminuria. The prescription of ARBs and direct vasodilators showed a significant difference among different stages of CKD.

Funding: No funding sources Conflict of interest: None declared

Ethical approval: The study was approved by the Institutional Ethics Committee

\section{REFERENCES}

1. Hamrahian SM. Management of hypertension in patients with chronic kidney disease. Curr hypertens Rep. 2017;19:43-7.

2. Yusufali AM, Khatib R, Islam S, Alhabib KF, Bahonar A, Swidan HM, et al. Prevalence, awareness, treatment and control of hypertension in four Middle East countries. J Hypertens.
2017;35:1457-64.

3. El-Aty MA, Meky FA, Morsi MM, Al-Lawati JA, El Sayed MK. Hypertension in the adult Omani population: predictors for unawareness and uncontrolled hypertension. J Egypt Public Health Assoc. 2015;90:125-32.

4. Magvanjav O, Cooper-DeHoff RM, McDonough CW, Gong Y, Segal MS, Hogan WR, et al. Antihypertensive therapy prescribing patterns and correlates of blood pressure control among hypertensive patients with chronic kidney disease. J Clin Hypertens. 2019;21:91-101.

5. Kalaitzidis RG, Elisaf MS. Treatment of hypertension in chronic kidney disease. Curr Hypertens Rep. 2018;20:64-6.

6. Gradman AH, Basile JN, Carter BL, Bakris GL. Combination therapy in hypertension. J Clin Hypertens. 2011;13:146-54.

7. Whelton PK, Carey RM, Aronow WS, Casey DE, Collins KJ, Dennison Himmelfarb C, et al. Guideline for the prevention, detection, evaluation, and management of high blood pressure in adults: A report of the American college of cardiology/ american heart association task force on clinical practice guidelines. J Am Coll Cardiol. 2018;71:2199-269.

8. Liu B, Wang Q, Wang Y, Wang J, Zhang L, Zhao M, On behalf of the C-Stride study group. Utilization of antihypertensive drugs among chronic kidney disease patients: Results from the Chinese cohort study of chronic kidney disease. J Clin Hypertens. 2020;22:57-64.

9. Sonawane KB, Qian J, Hansen RA. Utilization patterns of antihypertensive drugs among the chronic kidney disease population in the United States: A cross-sectional analysis of the national health and nutrition examination survey. Clin Ther. 2015;37:188-96.

10. Hess G, Hill J, Lau H, Dastani H, Chaudhari P. Medication utilization patterns and hypertensionrelated expenditures among patients who were switched from fixed-dose to free-combination antihypertensive therapy. PT. 2008;33(11):652-66.

Cite this article as: Al-Mirza A, Al-Subhi HR, Abdelrahman AM. Utilization patterns of antihypertensive drugs in the management of hypertension among patients with chronic kidney disease at a tertiary hospital. Int J Basic Clin Pharmacol 2021;10:466-70. 